\title{
AIP hamberdy
}

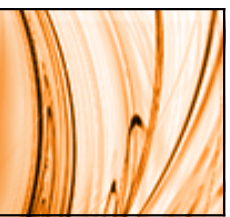

Influence of isochronal annealing on the microstructure and magnetic properties of $\mathrm{Cu}$ free HITPERM Fe40.5Co40.5Nb7B12 alloy

P. Gupta, Tapas Ganguli, A. Gupta, A. K. Sinha, S. K. Deb, P. Svec Jr., and V. Franco

Citation: Journal of Applied Physics 111, 113518 (2012); doi: 10.1063/1.4728161

View online: http://dx.doi.org/10.1063/1.4728161

View Table of Contents: http://scitation.aip.org/content/aip/journal/jap/111/11?ver=pdfcov

Published by the AIP Publishing

\section{Articles you may be interested in}

Effect of $\mathrm{Co}$ addition on the atomic ordering of FeCo-phase in nanocrystalline Fe81-xCoxNb7B12 alloys $(x=$ $20.25,27,40.5,54,60.75)$ : An anomalous diffraction and Mössbauer study

J. Appl. Phys. 114, 083516 (2013); 10.1063/1.4819398

The influence of isochronal annealing on the crystallization and magnetic properties of Fe40.5Co40.5Nb7B12 alloy

AIP Conf. Proc. 1447, 265 (2012); 10.1063/1.4709981

Secondary crystallization in (Fe65Co35)79.5+xB13Nb4-xSi2Cu1.5 and (Fe65Co35)83B10Nb4Si2Cu1 nanocomposite alloys

J. Appl. Phys. 111, $07 A 329$ (2012); 10.1063/1.3677830

Crystallization behavior and high temperature magnetic phase transitions of $\mathrm{Nb}$-substituted $\mathrm{FeCoSiBCu}$ nanocomposites

Appl. Phys. Lett. 99, 192506 (2011); 10.1063/1.3660245

The influence of microstructure on magnetic properties of nanocrystalline $\mathrm{Fe}-\mathrm{Pt}-\mathrm{Nb}-\mathrm{B}$ permanent magnet ribbons

J. Appl. Phys. 108, 093910 (2010); 10.1063/1.3504245

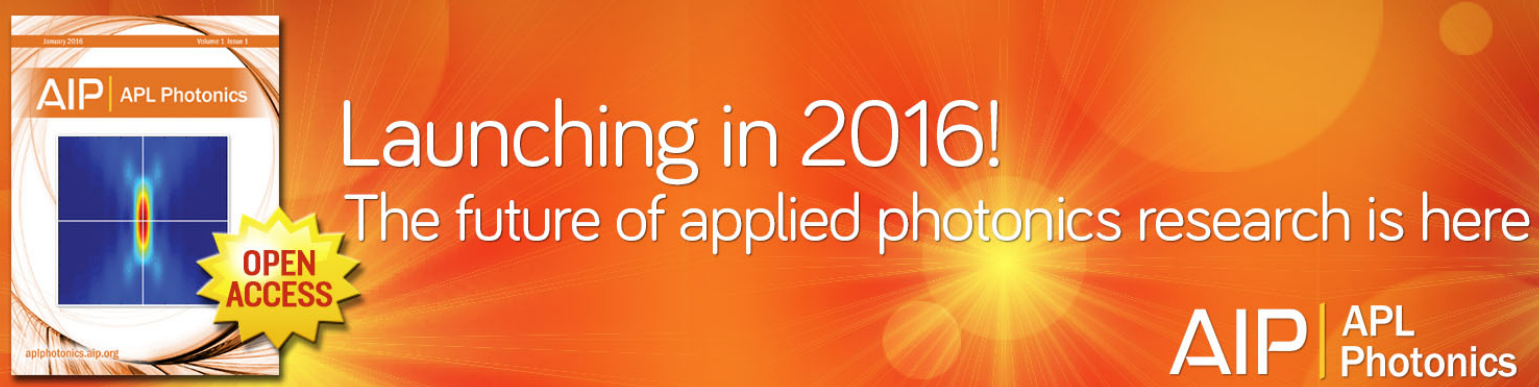




\title{
Influence of isochronal annealing on the microstructure and magnetic properties of $\mathrm{Cu}$-free HITPERM $\mathrm{Fe}_{40.5} \mathrm{Co}_{40.5} \mathrm{Nb}_{7} \mathrm{~B}_{12}$ alloy
}

\author{
P. Gupta, ${ }^{1}$ Tapas Ganguli, ${ }^{1}$ A. Gupta,${ }^{2}$ A. K. Sinha, ${ }^{1}$ S. K. Deb, ${ }^{1}$ P. Svec Jr.,${ }^{3}$ and V. Franco ${ }^{4}$ \\ ${ }_{1}^{1}$ Indus Synchrotron Utilization Division, Raja Ramanna Centre for Advanced Technology, Indore 452013, \\ India \\ ${ }^{2} U G C-D A E$ Consortium for Scientific Research, University Campus, Khandwa Road, Indore 452017, India \\ ${ }^{3}$ Institute of Physics, Slovak Academy of Sciences, Dubravska cesta 9, 84511 Bratislava, Slovakia \\ ${ }^{4}$ Dpto. Física de la Materia Condensada, ICMSE-CSIC, Universidad de Sevilla, P.O. Box 1065, Sevilla 41080, \\ Spain
}

(Received 28 January 2012; accepted 8 May 2012; published online 7 June 2012)

\begin{abstract}
Systematic study of the effect of isochronal annealing on the structure and magnetic properties of $\mathrm{Cu}$-free HITPERM alloy $\left(\mathrm{Fe}_{40.5} \mathrm{Co}_{40.5} \mathrm{Nb}_{7} \mathrm{~B}_{12}\right)$ is described herein. Mössbauer spectroscopy (MS) and anomalous X-ray diffraction (XRD) measurement at Fe K-edge $(7.112 \mathrm{keV})$ jointly provide clear evidence for the presence of atomically ordered $\alpha^{\prime}$-FeCo (B2 structure) phase as a nanocrystalline ferromagnetic phase. Being a short range order probe, Mössbauer spectroscopy also confirms the development of an additional non-magnetic $\mathrm{Nb}$-rich phase in the nanocrystalline specimens (annealed above $723 \mathrm{~K}$ ) with simultaneous lowering of the volume fraction of ferromagnetic phases. The fraction of Fe atoms in the non-magnetic phase is $\sim 15 \%$ upon annealing at $773 \mathrm{~K}$ for $1 \mathrm{~h}$, which increases gradually and reaches to as high as $\sim 19 \%$ after annealing at $923 \mathrm{~K}$. This phase was not detected by XRD and transmission electron microscopy (TEM) measurements, which may be attributed to tiny crystallite size and/or high degree of disorder. In the second stage of crystallization, i.e., above $923 \mathrm{~K}$, the alloy becomes fully crystalline and a stable, hard magnetic fcc- $(\mathrm{FeCo})_{23} \mathrm{~B}_{6}$ type phase was observed as a main boride phase along with soft magnetic $\alpha^{\prime}-\mathrm{FeCo}$ phase and $\mathrm{Nb}$ rich non-magnetic phase. Thermo magnetic measurement evidenced re-crystallization process as a considerable decrease in magnetization at the second transformation stage. Simultaneous lowering of the volume fraction of magnetic phases with the formation of non-magnetic phase provides convincing origin for the decrease in magnetization at the second crystallization stage. (C) 2012 American Institute of Physics. [http://dx.doi.org/10.1063/1.4728161]
\end{abstract}

\section{INTRODUCTION}

Nanocrystalline alloys, which consist of nanosized ferromagnetic crystals embedded in a residual ferromagnetic amorphous matrix, exhibit excellent soft magnetic properties such as low coercivity, high saturation magnetization, high permeability, and low hysteresis losses. Technical applications require materials with stable and good soft magnetic properties over a wide temperature and time range. Fe based nanocrystalline alloys produced by controlled partial crystallization of amorphous precursors (obtained by rapid quenching form the melt) are the best known soft magnetic materials till date. They can be classified as: FINEMET $(\mathrm{FeSiCuNbB}),{ }^{1}$ NANOPERM $(\mathrm{FeCu}(\mathrm{Zr}, \mathrm{Nb}, \mathrm{Hf}) \mathrm{B}){ }^{2}$ and HITPERM FeCo ( $\mathrm{Zr}, \mathrm{Nb}, \mathrm{Hf}) \mathrm{B}(\mathrm{Cu})^{3}$ alloys. The crystallization of such alloys occurs in two transformation stages, in the primary stage of crystallization $\alpha-\mathrm{Fe}_{3} \mathrm{Si}$ nanocrystalline grains with a $\mathrm{DO}_{3}$ crystal structure (for Finemet alloys), $\alpha$-Fe nanocrystals with body-centered-cubic (bcc) (A2) structure (for Nanoperm), nanocrystalline $\alpha^{\prime}$-FeCo grains with B2 structure (for HITPERM) are formed. Devitrification process is completed in the second transformation stage, occurring at higher temperature where abrupt decrease in soft magnetic properties is observed with the formation of different hard magnetic and/or non-magnetic boride and niobate phases.
In the nanocrystalline state, where the nanosized ferromagnetic crystalline grains are embedded in a residual ferromagnetic amorphous matrix, the soft magnetic properties arise from the exchange interaction between the randomly oriented nanocrystalline grains $(5-20 \mathrm{~nm})$ through the intervening amorphous matrix (atomic scale), ${ }_{1}^{1}$ where the smoothing action of exchange energy decreases the effective anisotropy. ${ }^{4}$ The exchange coupling among these grains deteriorates above the Curie temperature of amorphous matrix, which in turn deteriorates the soft magnetic properties in such systems. Therefore, FINEMET and NANOPERM alloys have low thermal limitation.

High temperature power applications require that the soft magnetic properties of these alloys should be maintained up to elevated temperatures. ${ }^{5}$ Due to presence of Co, HITPERM type alloys possesses high Curie temperature of amorphous and nanocrystalline phases and maintains high induction (1.6-2.1 T) up to elevated temperatures as compared to FINEMET and NANOPERM and thus are suitable materials for operation at high temperatures. ${ }^{6}$

$\mathrm{Cu}$ free HITPERM alloys possess lower values of coercivity as compared to $\mathrm{Cu}$ containing HITPERM alloys. ${ }^{7} \mathrm{In}$ addition to this, because $\mathrm{Cu}$ atoms do not form clusters, the grain sizes in the nanocrystalline state of $\mathrm{Cu}$-containing and $\mathrm{Cu}$-free alloys are found to be almost same. ${ }^{8}$ Therefore, $\mathrm{Cu}$-free alloys have the benefit of increasing the saturation 
magnetic flux density. ${ }^{9}$ However, it may be noted that the late transition metals ( $\mathrm{Zr}, \mathrm{Nb}, \mathrm{Mo}$ etc.) affects the driving force of the $\mathrm{Cu}$ clustering phenomenon for such alloys. ${ }^{10}$

The soft magnetic properties of such nanocrystalline alloys have strong correlation with how the nanocrystalline phases evolve upon heat treatment under suitable conditions. ${ }^{11}$ Therefore, the optimization of microstructure and magnetic properties under the influence of some processing technique (such as thermal processing) is important for application of these alloys as soft magnetic materials. Controlled annealing treatment can pave a way in controlling the magnetic properties of the amorphous as well as nanocrystalline phases and hence the soft magnetic properties of the alloy composition. The detailed investigation on the effect of annealing is expected to provide a better understanding of the microstructure and magnetic properties.

In addition to this, Willard et al. ${ }^{12}$ provided unambiguous evidence about the atomically ordered $\alpha^{\prime}$-FeCo phase as the nanocrystalline phase in $\mathrm{FeCoZrBCu}$ alloys. However, there is no experimental evidence, whether the $\mathrm{Cu}$ free Hitperm alloy has either an atomically ordered or a disordered FeCo nanocrystalline phase. It is important to note that due to similar atomic scattering factors of $\mathrm{Fe}$ and $\mathrm{Co}$, there is ambiguity in distinguishing between the disordered $\alpha$-FeCo phase and ordered $\alpha^{\prime}$-FeCo phase by the conventional XRD measurement, in the nanocrystalline state of such alloys. Close to the absorption edges of the constituents ( $\mathrm{Fe}$ or $\mathrm{Co}$ ), the anomalous scattering factors play an important role and the difference in the atomic scattering factors enhances significantly, which makes the observation of super lattice reflection possible, in case of the ordered phase. ${ }^{13}$

In the present work, melt spun $\mathrm{Fe}_{40.5} \mathrm{Co}_{40.5} \mathrm{Nb}_{7} \mathrm{~B}_{12}$ alloy was isochronally annealed at different temperatures over a wide range of temperatures and the relation between the microstructure and magnetic properties of the alloy was investigated using complementary techniques of synchrotron radiation based X-ray diffraction (SR-XRD), TEM, Mössbauer spectroscopy, differential scanning calorimetry (DSC), and thermo-magnetic gravimetery (TMG). The degree of atomic ordering of the nanocrystalline $\mathrm{FeCo}$ phase was also determined by anomalous $\mathrm{x}$-ray scattering measurement at Fe K-edge (7.112 keV).

\section{EXPERIMENTAL}

Alloy of nominal composition $\mathrm{Fe}_{40.5} \mathrm{Co}_{40.5} \mathrm{Nb}_{7} \mathrm{~B}_{12}$ was prepared by arc melting high purity electrolytic $\mathrm{Fe}, \mathrm{Co}, \mathrm{Nb}$, and $\mathrm{B}$ metals basis in an argon atmosphere. Amorphous ribbons, $6 \mathrm{~mm}$ wide and about $20 \mu \mathrm{m}$ thick, were produced from the ingots using a single wheel melt spinning technique. Chemical composition of the ribbon was checked by inductively coupled plasma spectroscopy and no detectable deviation from the nominal composition was observed. The ribbons were isochronally annealed for $1 \mathrm{~h}$ in a tubular furnace under vacuum atmosphere (better than $10^{-5}$ Torr) at temperatures ranging from $573 \mathrm{~K}$ to $973 \mathrm{~K}$. A differential scanning calorimeter was used to examine the crystallization temperatures of an as-cast ribbon. A scanning rate of $10 \mathrm{~K} / \mathrm{min}$ was used for temperatures between $300 \mathrm{~K}$ and
$873 \mathrm{~K}$. The structures of the as-spun and annealed ribbons were examined by SR-XRD and TEM. X-ray diffraction measurements were performed at ADXRD beamline of Indus- 2 synchrotron source, India, ${ }^{14}$ utilizing the monochromatic $\mathrm{x}$-rays of energy $15 \mathrm{keV}$. Image plate area detector was used to record the spectra. Lathanum hexaborate $\left(\mathrm{LaB}_{6}\right)$ was used as standard material for calibration. In order to distinguish ordered $\alpha^{\prime}$-FeCo phase from the disordered $\alpha$-FeCo phase, anomalous XRD measurements were also performed by choosing the x-ray energy of $7.112 \mathrm{keV}$ (Fe- $K$ edge). All samples for TEM were isochronally annealed in high vacuum (better than $7.5 \times 10^{-7}$ Torr) at different temperatures and subsequently polished by ion beam milling using Gatan PIPS. TEM observations were performed using JEOL 2000 FX. For all the annealed specimens, the ${ }^{57} \mathrm{Fe}$ Mössbauer measurements at room temperature in transmission geometry have been done using a ${ }^{57} \mathrm{Co}$ : Rh source and a constant acceleration Mössbauer drive. To characterize thermal behavior of the magnetization of the alloy, thermomagnetic gravimetery was performed using Perkin-Elmer TGA-7. After electronically cancelling the sample weight, an apparent weight was recorded after placing a magnet (magnetic field $\sim 20 \mathrm{mT}$ ) below the sample pan. Heating was then carried out from $323 \mathrm{~K}$ to $1123 \mathrm{~K}$ with a rate of $10 \mathrm{~K} / \mathrm{min}$. Changes in the magnetic force acting on the sample are related to the variations in magnetization with temperature and are recorded as apparent weight change of the sample.

\section{RESULTS AND DISCUSSION}

\section{A. DSC measurement}

Figure 1 shows the DSC thermogram of the as-quenched samples measured in the temperature range where the primary crystallization takes place. The exothermal peaks with onset at $\mathrm{T}_{\text {onset }}$ and the peak position at $\mathrm{T}_{\text {crys1 }}$ correspond to the formation of the nanocrystalline bcc-FeCo. For $\mathrm{Fe}_{40.5} \mathrm{Co}_{40.5} \mathrm{Nb}_{7} \mathrm{~B}_{12}$ alloy, $\mathrm{T}_{\text {onset }} \sim 742 \mathrm{~K}$ and $\mathrm{T}_{\text {crys1 }} \sim 768 \mathrm{~K}$ has been detected. It may be noted that $\mathrm{T}_{\text {onset }}$ is obtained as the intersection of the largest slope of the exothermal peak with the baseline of the DSC record and $\mathrm{T}_{\text {crys }}$ is the temperature of the peak. In general,

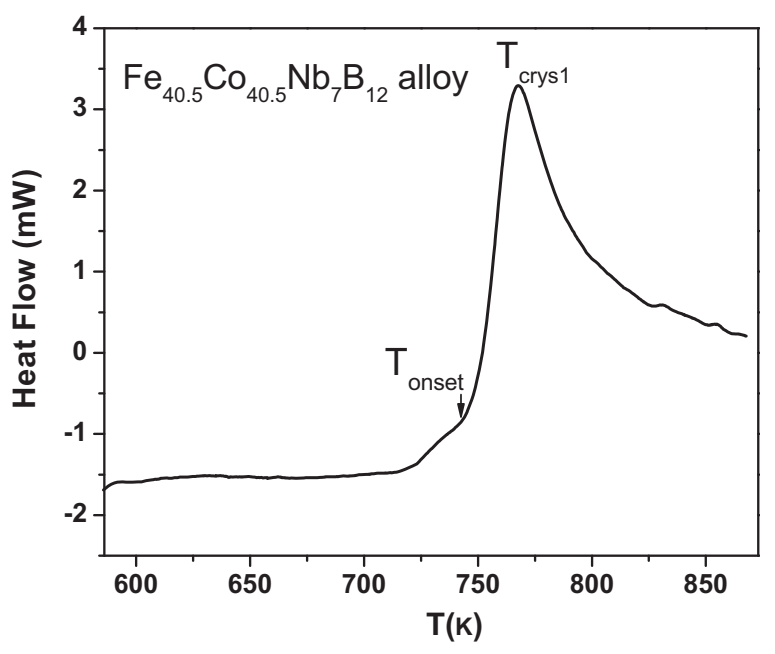

FIG. 1. DSC scan of as-cast $\mathrm{Fe}_{40.5} \mathrm{Co}_{40.5} \mathrm{Nb}_{7} \mathrm{~B}_{12}$ alloy. 
the Nb-containing HITPERM type alloys follow a two step crystallization process. ${ }^{15,16}$ The primary crystallization stage (above $700 \mathrm{~K}$ ) produces bcc-FeCo nanocrystals dispersed in residual amorphous matrix. The alloy becomes fully crystalline in a secondary crystallization stage (above $900 \mathrm{~K}$ ) with the precipitation of additional boride and niobate phases. ${ }^{17}$

\section{B. XRD measurement}

Figure 2 gives SR-XRD spectra of the alloy in the annealed state with some representative raw image plate patterns, illustrating the micro structural evolution of the samples as a function of annealing temperature. For comparison, the spectrum of the alloy in the as-quenched state is also included in the same figure. The sample-to-image-plate distance was $125.36 \mathrm{~mm}$. The image plate data files were integrated using FIT2D, incorporating polarization correction. ${ }^{18}$

In the as prepared state, XRD pattern shows a broad halo, which is characteristic of the amorphous phase. With progressive stages of annealing, the system gradually transforms to nanocrystalline phase. The XRD spectra of the asquenched alloy can be fitted by a Lorentzian function with full width at half maximum of $3.22^{\circ} \pm 0.02^{\circ}$. The XRD patterns of the annealed specimens show that after annealing at $723 \mathrm{~K}$ (temperature corresponds to onset of crystallization), the broad halo started shaping into narrow peak and the alloy becomes partially nanocrystalline, where nano-crystals are dispersed in the remaining amorphous matrix (Fig. 2). This nanocrystalline phase comprises of bcc-Fe (Co) phase as indicated by sharp peaks in the XRD pattern of the specimen annealed at $773 \mathrm{~K}$, at $2 \theta$ values of $23.51^{\circ}, 33.52^{\circ}, 41.36^{\circ}$, and $48.14^{\circ}$ with some small indication of amorphous phase. The relative intensities match well with the JCPDS database $^{19}$ and additionally the diffraction rings are of uniform

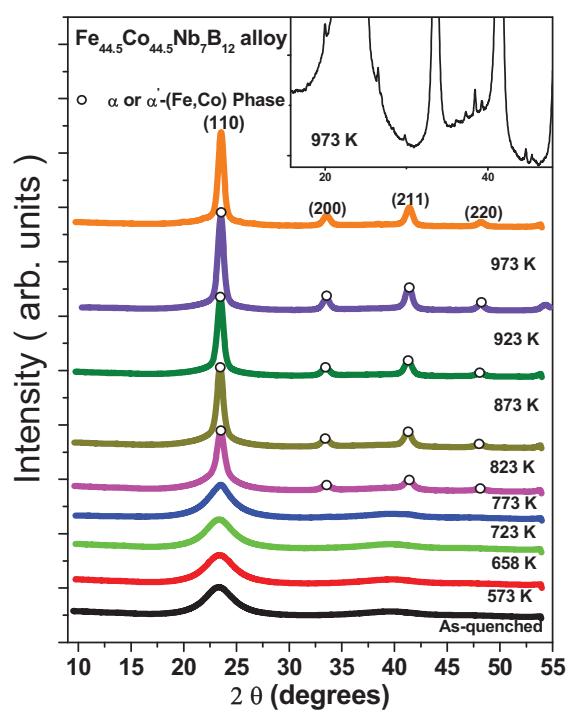

(a)

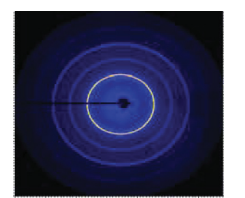

(iii)
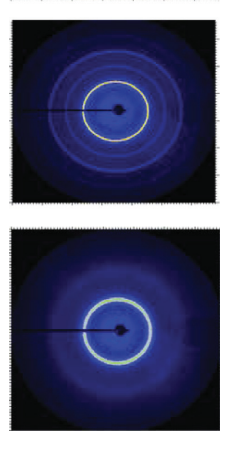

(ii)

(i)
FIG. 2. (a): XRD patterns of the $\mathrm{Fe}_{40.5} \mathrm{Co}_{40.5} \mathrm{Nb}_{7} \mathrm{~B}_{12}$ alloy after annealing up to the onset of second crystallization stage. For comparison XRD pattern of the as prepared sample is also shown. The beam energy used for these measurements was $15 \mathrm{keV}$. (b) Inset shows raw image plate $\mathrm{x}$-ray diffraction data for (i) as prepared sample, (ii) annealed at $873 \mathrm{~K}$, and (iii) annealed at $973 \mathrm{~K}$. intensity (Fig. 2(b)), which shows that the crystallites have random orientation. ${ }^{20}$

In case of annealed specimens, the assumption of single Lorentzian for the fitting was found to be valid only up to $658 \mathrm{~K}$, where the specimen remained in the pure amorphous state. From $723 \mathrm{~K}$ onwards, data were fitted by taking the superposition of Lorentzian and Gaussian peaks: Lorentzian corresponds to the amorphous phase and Gaussian to the nanocrystalline phase. It may be noted that with increasing annealing temperature (up to the temperature of $923 \mathrm{~K}$ ), diffraction peaks corresponding to bcc-FeCo nanocrystalline phase become progressively sharper but the peak position remains nearly unaffected for the whole range of annealing temperature. After annealing at $973 \mathrm{~K}$ (well above the end of primary crystallization), the peak corresponding to (110) reflection of $\mathrm{Fe}$, Co nanocrystalline phase becomes very sharp and the alloy becomes fully crystalline. No signature of the remaining amorphous phase was observed. Closer inspection of the spectra in the fully crystalline state of the alloy suggests that various additional small peaks start appearing which correspond to different boride-type phases such as $(\mathrm{FeCo})_{3} \mathrm{~B},(\mathrm{FeCo})_{2} \mathrm{~B}$ and $(\mathrm{FeCo})_{23} \mathrm{~B}_{6}$ phases and $(\mathrm{FeCo})_{3} \mathrm{Nb}$ niobate phase. ${ }^{15,17,21}$ Studies on the crystallization of FINEMET alloys have exhibited such hard magnetic boride phases upon joule heating. ${ }^{22}$

The average crystallite size (D) and lattice micro-strain (ع) for FeCo phase was estimated by applying the Williamson-Hall method. ${ }^{23}$ The physical line broadening B is a sum of line broadening connected to crystallite size (D) and of line broadening connected to lattice strain $(\varepsilon)$. For the Gaussian $\mathrm{x}$-ray profiles, Williamson-Hall equation is expresses as, ${ }^{24}$

$$
(B \cos \theta)^{2}=\left(\frac{k \lambda}{D}\right)^{2}+(\varepsilon \sin \theta)^{2},
$$

where $\mathrm{B}$ is the full width at half maximum of XRD peaks, $k$ is Scherrer constant, $\lambda$ is the wavelength of $\mathrm{X}$-ray, and $\theta$ is the Bragg angle. The line broadening and the position of the four Bragg peaks were used to estimate the mean crystallite size, (D) and lattice micro-strain ( $)$. Figure 3 shows the calculated $D$ and $\varepsilon$ values for the alloy as a function of increasing annealing temperature. The results indicate that the crystallite size increases with increasing annealing temperature. Upon annealing at $973 \mathrm{~K}$, when the system is completely crystallized, the size of crystallite further increases and attains a value of $\sim 13 \mathrm{~nm}$ (Fig. 3(a)). It may be noted that the refinement of grain size below ferromagnetic exchange length, $\mathrm{L}_{0}\left(\sim 46 \mathrm{~nm}\right.$ for equiatomic FeCo alloy $\left.{ }^{7}\right)$, is necessary to obtain superior soft magnetic properties in such alloys. ${ }^{25}$ Furthermore, the decrease in lattice micro-strain with temperature (Fig. 3(b)) indicates improved crystalline quality with increasing crystallite size of FeCo nanocrystalline phase.

The lattice parameter of the nanocrystalline phase, as calculated from the results of XRD measurements, initially exhibit a small decrease $(\sim 0.3 \%)$ with annealing temperature and then becomes almost constant for annealing temperatures greater than $823 \mathrm{~K}$ (Fig. 4). The decrease in lattice 


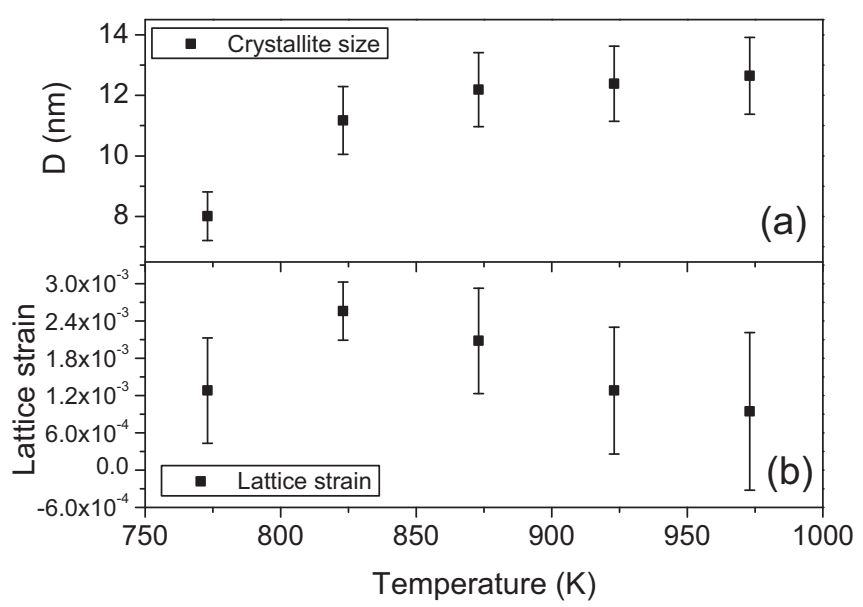

FIG. 3. Variation of crystallite size (D) and lattice micro-strain $(\varepsilon)$ of the FeCo nanocrystalline phase as a function of increasing annealing temperature.

parameter is correlated with the increase in crystallite size. Generally for such alloy systems, the density of crystalline phase is higher than that of the amorphous phase; therefore as the denser crystalline phase precipitates out, it will experience a tensile stress due to surrounding amorphous matrix. Therefore, the associated strain in crystalline FeCo phase will decrease with increasing crystallite size. This initial decrease in lattice parameter may thus be understood in terms of decrease in the effect of tensile stress exerted by the low density amorphous matrix on the nanocrystalline phase with increase in crystallite size. ${ }^{26}$

The ratio of the area of the nanocrystalline phase to that of the sum of the areas of the nanocrystalline and the amorphous phases was used to calculate the crystalline fraction of the nanocrystalline phase. ${ }^{27}$ As expected, with increasing crystallization, the crystalline fraction was found to be increasing, and finally at $973 \mathrm{~K}$, crystallization of nanocrystalline FeCo phase completes (full crystallization), and at this temperature, a very good fitting to the data was obtained by Gaussian profile corresponding to the single crystalline phase.

From the conventional XRD pattern, it is difficult to detect the correct structure (ordered or disordered) in case of alloys or compounds of the type $\mathrm{FeCo}, \mathrm{CuZn}$ etc, which

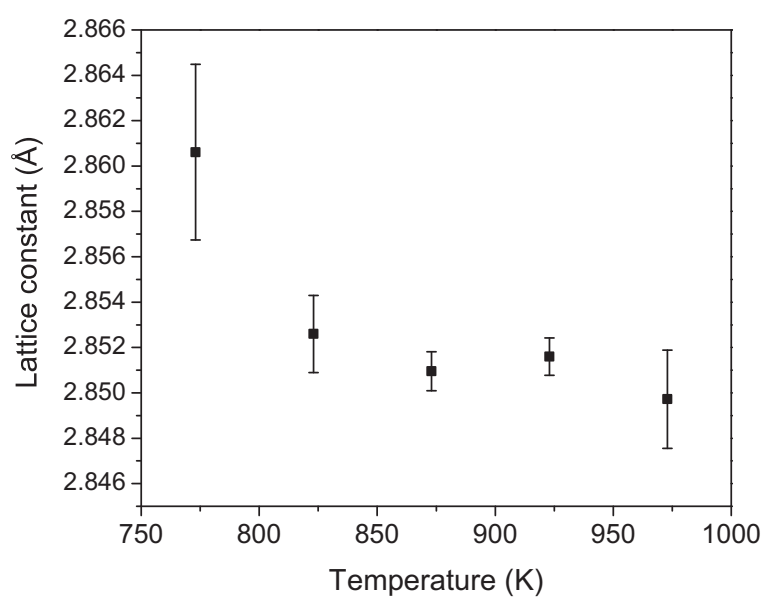

FIG. 4. Variation in lattice constant with increasing annealing temperature. differ in atomic number by only one or two units. It is because the superlattice (SL) line intensity is in general proportional to $\left(f_{A}-f_{B}\right)^{2}$, where $f_{A}$ and $f_{B}$ are atomic scattering factors of elements $\mathrm{A}$ and $\mathrm{B}$, respectively. The atomic scattering factors of element $\mathrm{A}$ and element $\mathrm{B}$ are very similar for excitation by a standard laboratory source $\left(\mathrm{Cu} \mathrm{K} \mathrm{K}_{\alpha}\right)$, and the SL intensity is, therefore, very weak as compared to fundamental line (FL) intensity. ${ }^{13}$ However, the correct structure can be obtained when the incident wavelength $\lambda$ is nearly equal to wavelength $\lambda_{\mathrm{K}}$ of the K-absorption edge of the one of the scattering element (either A or B). Close to the absorption edges of the constituents ( $\mathrm{Fe}$ or $\mathrm{Co}$ in case of FeCo alloy), the atomic scattering factors of the scattering elements get significantly modified due to the contribution of anomalous dispersion effects. This increases the differences in the atomic scattering factors between the elements, thereby enhancing the intensity of the superlattice reflection relative to that of the fundamental line and hence makes the observation of super lattice reflection possible, in case of an ordered structure.

In the complete ordered state of FeCo alloy, each unit cell will contain one $\mathrm{Fe}$ atom, at $(0,0,0)$ and one Co atom at $(1 / 2,1 / 2,1 / 2)$. Therefore, the structure factor,

$$
\begin{aligned}
& F=f_{F e}+f_{C o}\left[e^{\pi i(h+k+l)}\right], \\
& F=f_{F e}+f_{C o} \text { for }(\mathrm{h}+\mathrm{k}+1) \text { even, } \\
& F=f_{F e}-f_{C o} \text { for }(\mathrm{h}+\mathrm{k}+1) \text { odd. }
\end{aligned}
$$

The ordered structure thus produces diffraction lines for all values of hkl, and therefore, it resembles the diffraction pattern of a simple cubic substance. For a fully ordered alloy, intensity of SL line (100) relative to that of the fundamental line (110) can be estimated as

$$
\begin{aligned}
\operatorname{intensity}(\mathrm{SL}) / \text { intensity }(\mathrm{FL})= & p \times\left(\frac{1}{\sin ^{2} \theta \cos \theta}\right) \\
& \times\left(\frac{\left(f_{F e}-f_{C o}\right)^{2}}{\left(f_{F e}+f_{C o}\right)^{2}}\right)
\end{aligned}
$$

where $\mathrm{p}$ is the multiplicity factor and the trigonometric terms correspond to the Lorentz factor. When $\lambda$ is near $\lambda_{\mathrm{k}}$, the atomic scattering factor would be

$$
F=f_{0}+\Delta f
$$

where $f_{0}$ is the atomic scattering factor when $\lambda \ll \lambda_{k}$ and $\Delta f$ is change in $f_{0}$ when $\lambda$ is near $\lambda_{k}$. Here, $\lambda / \lambda_{\mathrm{k}}$ is $\sim 1.00$ for the $\mathrm{Fe}$ atom and 1.08 for Cobalt atom, and the value of $\Delta f$ is then about -5.0 for $\mathrm{Fe}$ atom and -2.7 for Cobalt atom; ${ }^{13}$ therefore at a $2 \theta$ value of $35.71^{\circ}$ (where the SL peak is observed experimentally), the intensity of the SL reflection would be proportional to $\sim 10.4$ including the multiplicity factor and Lorentz factor. The ratio of the SL reflection relative to FL reflection is evaluated to be 0.012 . However, this ratio corresponds to 0.00035 when $\lambda \ll \lambda_{k}$. In the present case, anomalous XRD measurements was performed at Fe K-edge $(7.112 \mathrm{keV})$ for the specimen annealed at $823 \mathrm{~K}$ for 


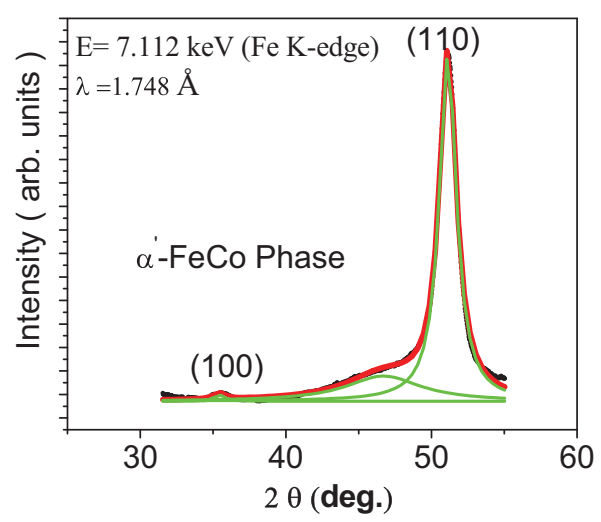

FIG. 5. SR-XRD measurement at $7.112 \mathrm{keV}$ confirms the ordered $\alpha^{\prime}$-Fe, Co phase by the presence of (100) super lattice reflection.

detection of correct structure (ordered or disordered) of $\mathrm{Fe}_{40.5} \mathrm{Co}_{40.5} \mathrm{Nb}_{7} \mathrm{~B}_{12}$ alloy and is shown in Fig. 5. Presence of weak (100) super-lattice reflection along with the (110) fundamental reflection indicate the presence of atomically ordered FeCo nanocrystalline phase having B2 structure. The diffraction pattern was fitted by a superposition of three Lorentzian peaks: one corresponds to (100) SL reflection and the other two correspond to amorphous and nanocrystalline phases of (110) reflections. The integrated intensity ratio of (100) SL reflection relative to that of (110) reflection is estimated as $\sim 0.0117$. This is in good agreement (within 2.5\%) with the calculated intensity ratio. It may be noted that the ordering of $\alpha$-FeCo nanocrystalline phase in such alloys depends on $\mathrm{Fe}$, Co composition ${ }^{28,29}$ as well as on the preparation conditions. ${ }^{30}$

Further, XRD measurements also provide detailed information about the structural changes occurring in the remaining amorphous grain-boundary phase. In the amorphous phase, the atoms do not have a long range order and only short range order exists. The short range order can be expressed by a radial distribution function $4 \pi r^{2} \rho(r)$ such that $4 \pi r^{2} \rho(r) d r$ is the average number of atoms centers between $r$ and $r+d r$ from the centre of an average atom. ${ }^{31}$ The radial distribution function is given by

$$
4 \pi r^{2} \rho(r)=4 \pi r^{2} \rho_{o}(r)+\frac{2 r}{\pi} \int_{0}^{\infty} k i(k) \sin (r k) d k
$$

where $\rho_{o}(r)$ is the average density in atoms $/ \AA^{3}, k=\frac{4 \pi \sin (\theta)}{\lambda}$ is reciprocal lattice vector $\left(\AA^{-1}\right)$, and $i(k)$ is the modified scattering intensity. It may be noted that the expression above is valid for the amorphous sample containing only one kind of atom. In the FeCoNbB alloy under study, Fe and Co have very close atomic numbers and they form about $81 \%$ of composition, B forms $12 \%$ of composition but it is a poor $\mathrm{x}$-ray scatterer and $\mathrm{Nb}$ forms only $7 \%$ of the composition, whose contribution in scattering is small and thus ignored. Considering only one kind of atom, the radial distribution function has been calculated for the as-quenched as well as annealed $\mathrm{Fe}_{40.5} \mathrm{Co}_{40.5} \mathrm{Nb}_{7} \mathrm{~B}_{12}$ alloy before the onset of crystallization. For all the samples in the pure amorphous state, TM-TM distance is found to be nearly identical and equals to $\sim 2.69 \AA$, where TM denotes transition metal. Figure 6

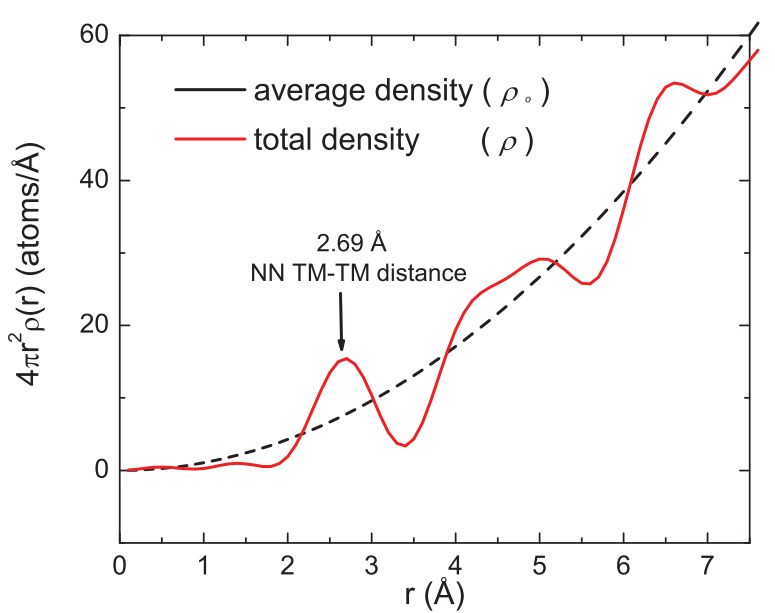

FIG. 6. Radial distribution function of the $\mathrm{Fe}_{40.5} \mathrm{Co}_{40.5} \mathrm{Nb}_{7} \mathrm{~B}_{12}$ alloy in its pure amorphous state.

shows the representative radial distribution function (RDF) for the sample annealed at $658 \mathrm{~K}$, where the alloy remains in the pure amorphous phase. In general, the position of the first broad maximum can be used to calculate the distance between the nearest neighbor atoms $\left(X_{\mathrm{m}}\right)$ in the amorphous phase using the relation, $C \lambda=2 X_{m} \sin \theta$, where $C$ is a constant and generally taken as $1.23 .{ }^{32}$ Upon comparison of the transition metal-transition metal (TM-TM) distance as obtained from the RDF, the value of $C$ was found to be $\sim 1.31$ for the present set of experiments. This has been used to estimate the TM-TM distance, from the amorphous contribution, in the partially crystalline samples. Figure 7 gives the variation in the average TM-TM nearest neighbour distance in the amorphous phase, as obtained from the position of the broad amorphous peak. Before nanocrystallisation, the TMTM distance decreases slightly, this could be understood in terms of structural relaxation, which is expected to result in annihilation of defects and excess free volume and thus should result in a decrease in the TM-TM nearest neighbor distance. A monotonous increase in the TM-TM distance upon nanocrystallisation may be attributed to enrichment of the amorphous phase in metalloid. ${ }^{33}$ It may be noted that the $\mathrm{x}$-ray scattering from the metalloid atoms is significantly

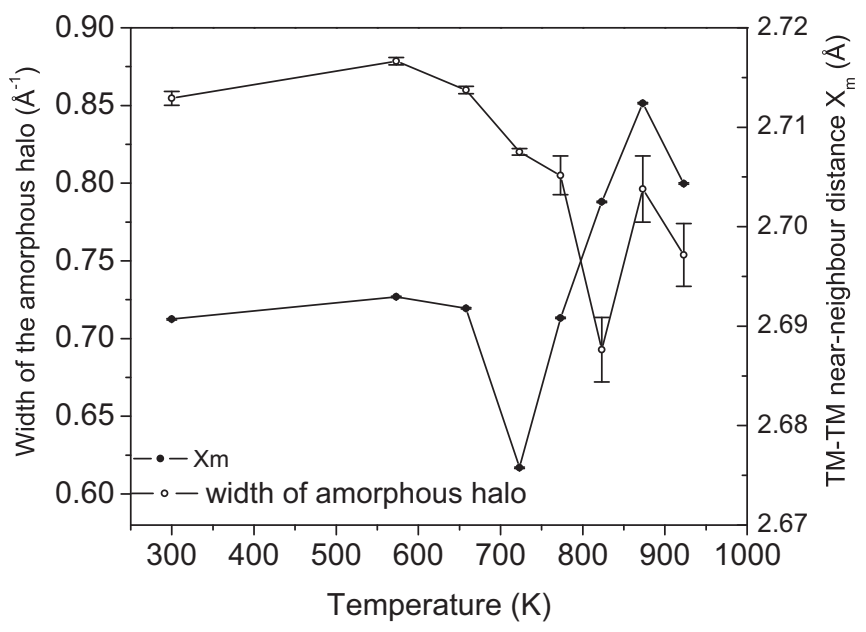

FIG. 7. Average TM-TM nearest neighbour distance and width of the amorphous halo as a function of annealing temperature. 
weak as compared to that from the TM atoms. The width of the amorphous halo of the XRD pattern, which is a measure of the degree of disorder in the amorphous phase, exhibits an interesting behavior with annealing temperature, as shown in Figure 7. This behaviour may be understood as follows. Initially, annealing in the temperature range $573-823 \mathrm{~K}$ causes a decrease in the disorder. This may be connected to structural relaxation in the amorphous phase, which results in an increased topological order in the system. Annealing at higher temperatures results in a sharp increase in the disorder and then shows a rapid decrease. Initially, with increasing crystallization, as metalloid is expelled out of nanocrystalline grains, it will form a concentration gradient around the crystallites. However, for higher annealing temperature metalloid distributes rather uniformly throughout the amorphous phase, resulting in a relatively homogeneous distribution. ${ }^{33}$ This redistribution affects the magnetic properties of the amorphous phase and the soft magnetic properties of the nanocrystalline alloy.

\section{Transmission electron microscopy}

The microstructure and selected area electron diffraction patterns of the sample in different stages of transformation are shown in Figs. 8(a) and 8(b). The observed grain sizes of the bcc-phase (Fig. 8(a)-insets (i)-(iii)) are in accordance with the values determined from XRD analysis. TEM images show that there is no significant size evolution of the bccphase particles with annealing temperature. However, the particles seem to be distributed in a not completely random manner (see images in Fig. 8(a)-insets (i) and (ii)); this effect is enhanced in the stages prior to the formation of the $(\mathrm{FeCo})_{23} \mathrm{~B}_{6}$ type phase and possibly reflects the mediumrange order, which may be a precursor to the formation of complex $(\mathrm{FeCo})_{23} \mathrm{~B}_{6}$ phase. The particles of this phase, especially in the final stage of its formation, seem to consist of several grains and range up to $300 \mathrm{~nm}$ in size. No preferential orientation of the fcc-phase with respect to the ribbon surface has been observed. It is to be noted that the particles of bcc-
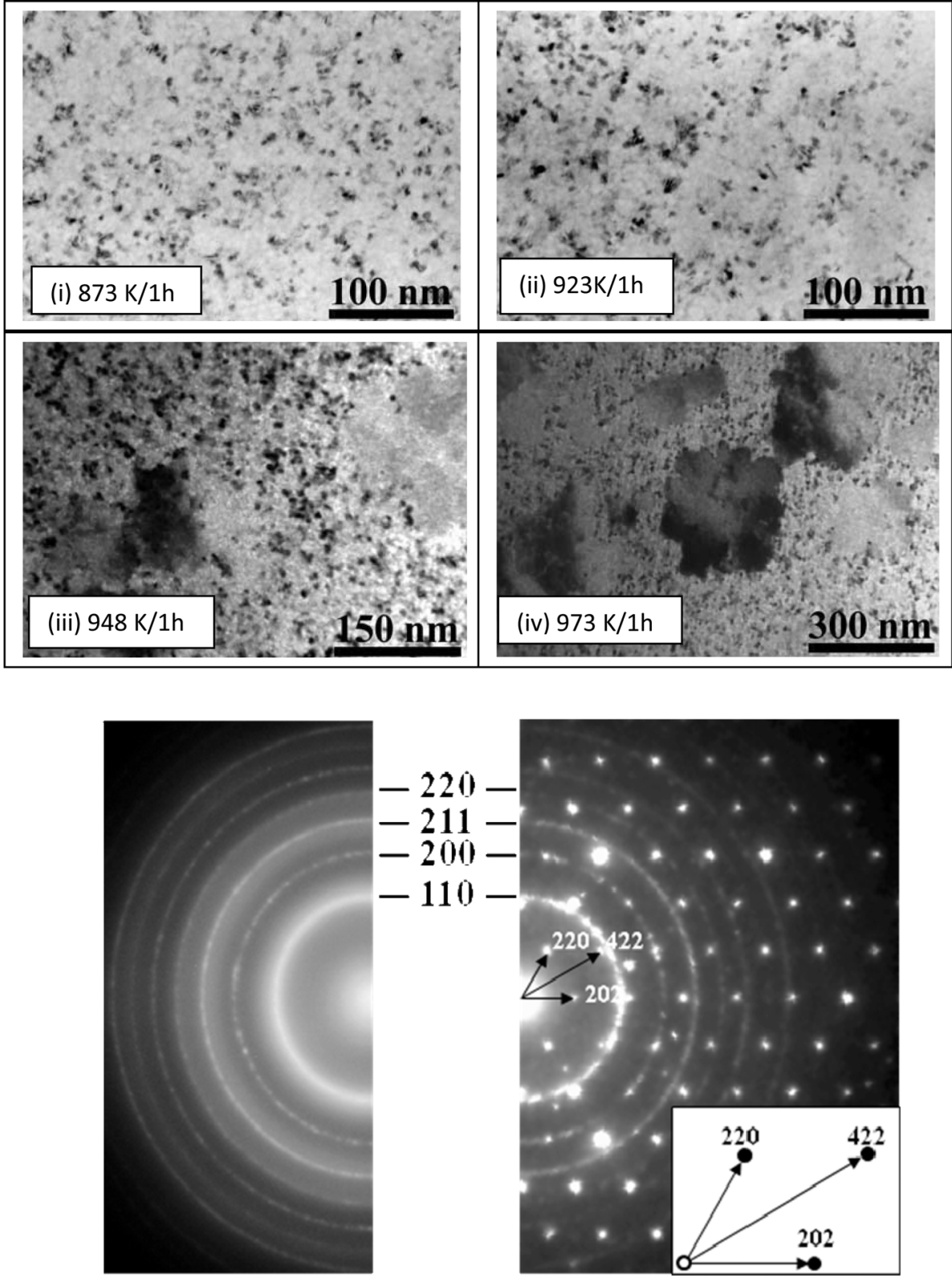

FIG. 8. (a) Evolution of morphology during transformation from amorphous state (bright field images): final stages of nanocrystallisation, sample annealed at $873 \mathrm{~K} / 1 \mathrm{~h}$ (i) and $923 \mathrm{~K} / 1 \mathrm{~h}$ (ii) initial stages of formation of $(\mathrm{FeCo})_{23} \mathrm{~B}_{6}$ phase, sample annealed at $948 \mathrm{~K} / 1 \mathrm{~h}$ (iii) completely crystallized sample annealed at $973 \mathrm{~K} / 1 \mathrm{~h}$ (iv) with fully developed grains of $(\mathrm{FeCo})_{23} \mathrm{~B}_{6}$. (b) Left-diffraction pattern from the sample annealed at $923 \mathrm{~K} / 1 \mathrm{~h}$ showing the presence of bcc-Fe (Co) phase (indices in the central part of the image) with traces of amorphous remains. Right-diffraction pattern from the central particle in (a) (iii) $(973 \mathrm{~K} / 1 \mathrm{~h}$, bright field) showing the presence of fccphase of the $(\mathrm{FeCo})_{23} \mathrm{~B}_{6}$ type (zone axis $111)$ together with rings of bcc-Fe (Co). 
Fe (Co) retain their small size even after full crystallization of the sample.

\section{Mössbauer measurements}

Mössbauer spectroscopy has been used as a complementary tool for the determination of the structure and magnetic properties of the $\mathrm{Fe}_{40.5} \mathrm{Co}_{40.5} \mathrm{Nb}_{7} \mathrm{~B}_{12}$ alloy as a function of isochronal annealing. Figure 9 represents Mössbauer spectra of the alloy along with the fittings in the as-quenched state as well as after isochronal annealing at various temperatures up to $973 \mathrm{~K}$. In the present study, the fitting of the Mössbauer spectra has been performed using the NORMOS program, which allows a simultaneous fit of several crystalline spectra with possible addition of an amorphous phase. ${ }^{34}$ The asquenched alloy consists of a broad sextet typical of amorphous phase (Fig. 9). The alloy remains in fully amorphous state only up to the annealing temperature of $658 \mathrm{~K}$, clear evidence of the onset of crystallization was observed after annealing at $723 \mathrm{~K}$ (Fig. 9). The Mössbauer spectra of the alloy in as-quenched state as well as after annealing (up to the temperature of $723 \mathrm{~K}$ ) were analyzed using NORMOS (DIST) program, in terms of a distribution of hyperfine fields representing the distribution of local environment around the $\mathrm{Fe}$ atoms. In the as quenched state, the Mössbauer spectrum has been fitted closely by the average magnetic hyperfine field $\left(\left\langle\mathrm{B}_{\mathrm{hf}}\right\rangle\right)$ value of $\sim 23.8 \pm 0.2 \mathrm{~T}$ for an amorphous sextet. Upon annealing, the $\left\langle\mathrm{B}_{\mathrm{hf}}\right\rangle$ value increases, reaching a value of $24.2 \pm 0.1 \mathrm{~T}$ at $723 \mathrm{~K}$. This suggests an increase in topological ordering in the system, which corroborates the SRXRD results. Figure 10 presents resultant hyperfine field distribution of the alloy in the amorphous phase (up to $658 \mathrm{~K}$ ) and upon evolution of the nanocrystalline phase (at $723 \mathrm{~K}$ ). The Hyperfine field distribution in the amorphous phase

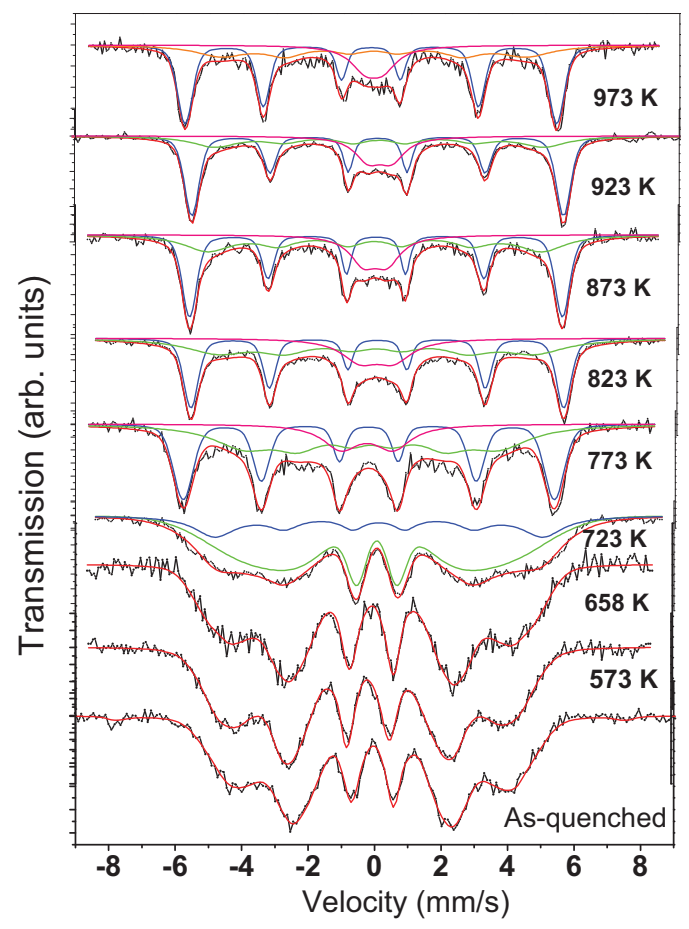

FIG. 9. Mössbauer spectra along with the fittings of the $\mathrm{Fe}_{40.5} \mathrm{Co}_{40.5} \mathrm{Nb}_{7} \mathrm{~B}_{12}$ alloy as a function of increasing annealing temperature.

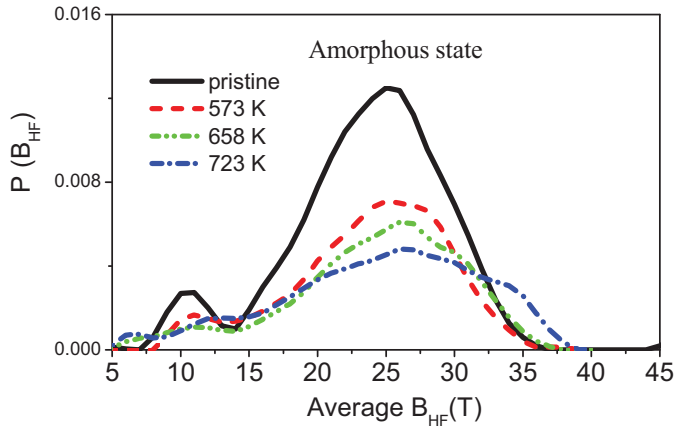

FIG. 10. Hyperfine field distribution of $\mathrm{Fe}_{40.5} \mathrm{Co}_{40.5} \mathrm{Nb}_{7} \mathrm{~B} 3_{12}$ alloy up to the annealing temperature of $723 \mathrm{~K}$.

consists of two broad humps: A broad hump with a maximum of $\left\langle\mathrm{B}_{\mathrm{hf}}\right\rangle$ at around $25 \mathrm{~T}$ and a smaller hump with a maximum of $\left\langle\mathrm{B}_{\mathrm{hf}}\right\rangle$ around $10 \mathrm{~T}$. The smaller hump represents the $\mathrm{Fe}$ atoms having $\mathrm{Nb}$ nearest neighbors $(\mathrm{NN})$. It is known that the presence of $\mathrm{Nb}$ in the first coordination shell of Fe significantly reduces the hyperfine field of $\mathrm{Fe}$ atoms. ${ }^{35} \mathrm{In}$ the amorphous state of the alloy $\mathrm{P}\left(\left\langle\mathrm{B}_{\mathrm{hf}}\right\rangle\right)$ of the peaks around $25 \mathrm{~T}$ and around $10 \mathrm{~T}$ decrease with annealing temperature (Fig. 10). These changes correspond to the elements redistribution in totally amorphous alloy during the structural relaxation. Since Mössbauer measurement shows only the nearest environment of $\mathrm{Fe}$ atoms, this spatial distribution of elements during compositional fluctuation can be interpreted as a decrease in the number of $\mathrm{Fe}-\mathrm{Fe} \mathrm{NN}$ as well as $\mathrm{Fe}-\mathrm{Nb}$ $\mathrm{NN}$. This suggests that both the on-site moment $(\mathrm{Fe}-\mathrm{Fe})$ and the surrounding moments $(\mathrm{Fe}-\mathrm{Nb})$ are decreasing with increase in annealing temperature. Additionally, ordering in the peaks at $25 \mathrm{~T}$ and $10 \mathrm{~T}$ is clearly seen by the decrease in the width of $\left\langle\mathrm{B}_{\mathrm{hf}}\right\rangle$ distribution with annealing temperature. Upon annealing at $723 \mathrm{~K}$, an additional hump around $34 \mathrm{~T}$ is clearly seen, which gives a signature of the onset of ordering of the nanocrystalline $\alpha^{\prime}$-FeCo phase. XRD and DSC measurements also support this observation.

The Mössbauer spectra of the alloys annealed at and above $723 \mathrm{~K}$ show clear evidence of the crystallization (Fig. 9). Therefore, the detail fitting of the spectra after crystallization was done using NORMOS (SITE) by considering two overlapping sextets: a sharp sextet corresponding to the bcc-FeCo nanocrystalline phase and a relatively broad sextet indicating the remaining amorphous phase. It may be noted that, in order to get best fitting in crystalline state of the alloy, an additional doublet corresponding to Nb-rich non magnetic phase was also included in the fitting model for alloys annealed at and above $773 \mathrm{~K}$. Evidence of the formation of such non magnetic niobate phase was also observed after annealing at $773 \mathrm{~K}$ in earlier studies in the nanocrystallisation stage. ${ }^{36}$

The fitting of the Mössbauer spectra after annealing at $773 \mathrm{~K}$ suggests that nearly $46 \%$ of Fe resides in the amorphous state. The presence of the hyperfine field components of $34.5 \pm 0.1 \mathrm{~T}$ shows the presence of bcc-FeCo nanocrystalline phase. ${ }^{15}$ The volume fraction of the non-magnetic component is $\sim 14.8 \%$ with the quadrupole splitting of $1.56 \pm 0.05 \mathrm{~mm} / \mathrm{s}$. It may be noted that the line widths of the quadrupole doublet as obtained from the fitting is very large; 
this suggests that $\mathrm{Nb}$-rich phase is in a disordered state. This disorder results in the distribution of quadrupole splitting.

Further annealing at higher temperatures of $823 \mathrm{~K}$ and $873 \mathrm{~K}$ causes the specimen to consist of FeCo nanocrystalline phase with a crystalline fraction of $\sim 42 \%$ and $\sim 47 \%$, respectively. However, the spectrum has been best fitted with crystalline sextets having internal magnetic field $\left\langle\mathrm{B}_{\mathrm{hf}}\right\rangle$ of $34.6 \pm 0.1$ and $34.5 \pm 0.1 \mathrm{~T}$, respectively. The volume fraction of the non-magnetic component was also found to be increasing and reaches to $18.4 \%$ after annealing at $873 \mathrm{~K}$. On the other hand, its quadrupole splitting decreased to $0.71 \pm 0.04 \mathrm{~mm} / \mathrm{s}$. After annealing at $923 \mathrm{~K}$, the spectrum was best fitted with $\left\langle\mathrm{B}_{\mathrm{hf}}\right\rangle$ value of $34.2 \pm 0.1 \mathrm{~T}$, corresponding to FeCo nanocrystalline phase, with increased crystalline fraction of $\sim 54 \%$. The volume fraction of non-magnetic component becomes $\sim 19 \%$, with quadrupole splitting of $0.70 \pm 0.02 \mathrm{~mm} / \mathrm{s}$.

Annealing at a temperature of $973 \mathrm{~K}$ results in the complete crystallization of the alloy. The best fitting of the spectrum has been obtained with $\left\langle\mathrm{B}_{\mathrm{hf}}\right\rangle$ of $34.3 \pm 0.1$ and $28.2 \pm 0.1 \mathrm{~T}$ corresponding to $\mathrm{FeCo}$ and $(\mathrm{FeCo})_{23} \mathrm{~B}_{6}$, phases, respectively, ${ }^{22,37}$ no trace of any remaining amorphous matrix was observed. However along with nanocrystalline FeCo phase and boride phase, the presence of non-magnetic phase was still observed with volume fraction of $\sim 16.5 \%$ and quadrupole splitting of $\sim 0.53 \pm 0.07 \mathrm{~mm} / \mathrm{s}$. Decrease of quadrupole splitting with annealing temperature indicated possible ordering of the $\mathrm{Nb}$-rich non-magnetic phase which can be attributed to $(\mathrm{FeCo})_{3} \mathrm{Nb}$ phase. ${ }^{36}$

Furthermore, the A23 parameter (the area ratio of the second and third lines of the Mössbauer spectra) gives information about the orientation of the magnetic moment. It was found that the A23 parameter for as-quenched alloy is $2.6 \pm 0.1$, which suggests that orientation of spins is not random rather they have some preference for the in-plane orientation. The A23 parameter decreases with annealing and becomes $1.2 \pm 0.1$ upon annealing at $923 \mathrm{~K}$, which indicates that the orientation of spins is preferentially out-of plane. Upon further annealing at $973 \mathrm{~K}$, A23 parameter becomes almost $2.0 \pm 0.1$, which shows that spins are randomly oriented. Thus, upon annealing, magnetic moments are changing their orientation from in-plane to out-of-plane to random. ${ }^{38}$ It may be noted that studied alloy exhibit strong perpendicular magnetic anisotropy in the annealing temperature range of $723 \mathrm{~K}-923 \mathrm{~K}$ (first transformation stage). In the mentioned temperature range, the alloy has peculiar two phase microstructure consisting of FeCo nano-crystals and the remaining amorphous phase, as otherwise, spins are oriented either in-plane or random.

The ordered $\alpha^{\prime}$-FeCo phase has lower values of $\left\langle\mathrm{B}_{\mathrm{hf}}\right\rangle$ as compared to disordered $\alpha$-FeCo phase (33.6 T and 35.7 T, respectively). ${ }^{15,29}$ In the present case, $\left\langle\mathrm{B}_{\mathrm{hf}}\right\rangle$ value of the nanocrystalline $\mathrm{FeCo}$ phase is ranging from $34.2 \mathrm{~T}$ to $34.6 \mathrm{~T}$. It is clear that low field contributions (close to $33 \mathrm{~T}$ ) are predominant, as is found in the $\mathrm{FeCo}$ atomically ordered structure. ${ }^{28}$

In the second crystallization stage ( $973 \mathrm{~K})$, as depicted by Mössbauer measurements, the coexistence of ordered $\alpha^{\prime}$-FeCo nanocrystalline soft magnetic phase and hard magnetic
$(\mathrm{FeCo})_{23} \mathrm{~B}_{6}$, phase has also been confirmed with SR-XRD measurements. Mössbauer measurements also support the presence of $\mathrm{Nb}$ rich non-magnetic phase in nano-crystalline specimens annealed at the temperature greater than $723 \mathrm{~K}$. However, the presence of the same has not been detected through XRD measurement up to $923 \mathrm{~K}$. This may be attributed to smaller crystallite size and/or high degree of disorder. ${ }^{39}$ It is important to note that the width of hyperfine field distribution of Mössbauer spectrum depends mainly on the chemical short range order; thus, it can be utilized to identify phases whose dimensions are too small for XRD measurements. ${ }^{40}$

Thus in concurrence with anomalous diffraction measurements, Mössbauer measurements also supports the nanocrystalline phase in $\mathrm{Fe}_{40.5} \mathrm{Co}_{40.5} \mathrm{Nb}_{7} \mathrm{~B}_{12}$ alloy has an atomically ordered $\alpha^{\prime}-\mathrm{FeCo}$ (B2) structure. ${ }^{41}$

\section{E. Thermomagnetic measurements}

TMG measurements were performed to detect the crystallization of ferromagnetic phases in $\mathrm{Fe}_{40.5} \mathrm{Co}_{40.5} \mathrm{Nb}_{7} \mathrm{~B}_{12}$ alloy. Figure 11 shows the temperature dependence of the low field $(20 \mathrm{mT})$ magnetization. For comparison, DSC plot is also included in the same figure. Upon heating, there is a first decrease in magnetization (M) due to approaching the Curie temperature $\left(T_{c}\right)$ of the initial amorphous phase. However, it does not fall to zero because the nanocrystallisation of bcc-( $\mathrm{Fe}, \mathrm{Co})$ phase takes place before $\mathrm{T}_{\mathrm{c}}$ is reached (as evidenced by the DSC record and the evolution of the XRD spectra). The onset of nanocrystallisation produces an increase in magnetization due to the appearance of the ferromagnetic bcc-(Fe, Co) phase, which has a larger Curie temperature. The overlapping of those two competing effects (decrease in $\mathrm{M}$ due to the Curie temperature of the amorphous phase and increase in $\mathrm{M}$ due to the formation of the ferromagnetic phase) alters the shape of the $M(T)$ curve, which decreases more slowly than a typical ferroparamagnetic transition. The increase of the crystalline fraction of the nanophase produces a larger increase in M. After reaching a maximum, magnetization decreases further. This decrease could be either due to a Curie transition or due to further crystallization of the alloy, where the existing bcc-

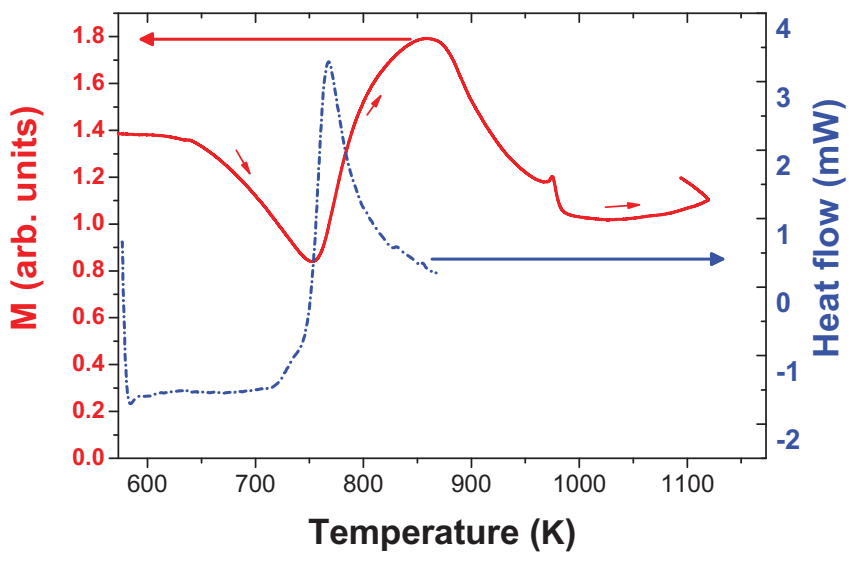

FIG. 11. Temperature dependence of the low field magnetization of asquenched $\mathrm{Fe}_{40.5} \mathrm{Co}_{40.5} \mathrm{Nb}_{7} \mathrm{~B}_{12}$ alloy (upon heating) along with DSC scan up to first crystallization stage. 


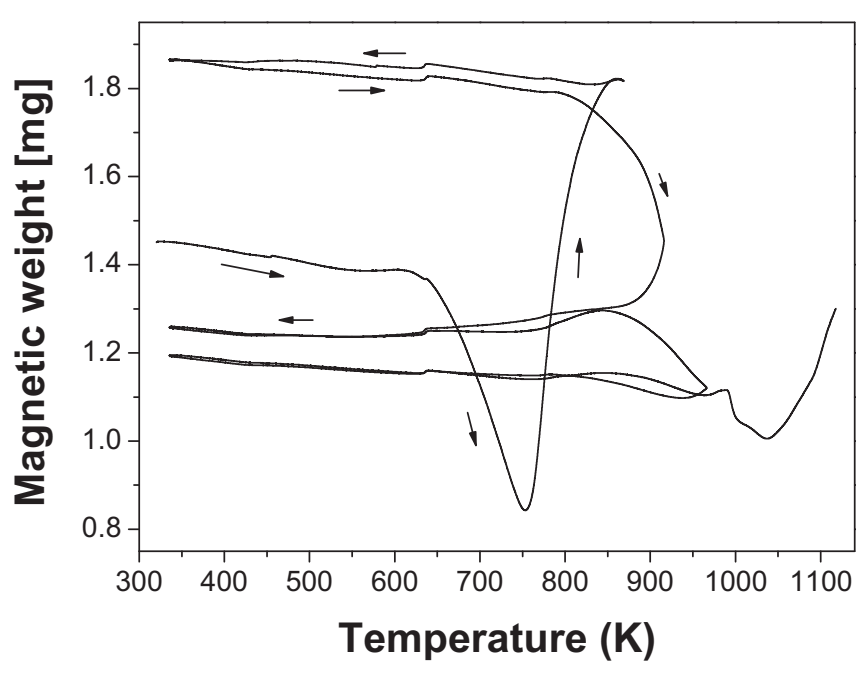

FIG. 12. TMG plot on successive heating-cooling cycles for the $\mathrm{Fe}_{40.5} \mathrm{Co}_{40.5} \mathrm{Nb}_{7} \mathrm{~B}_{12}$ alloy.

(Fe, Co) nanocrystals are transformed into another phase which has a lower magnetization.

It may be noted that the temperature corresponding to this decrease in magnetization is lower than the expected value for Curie temperature for binary $\mathrm{FeCo}$ alloys. ${ }^{40}$ In order to clarify which of these two reasons is responsible for this reduction in $\mathrm{M}$ above $\sim 873 \mathrm{~K}$, continuous heating and cooling experiments have been performed (Fig. 12). It is seen that the thermal evolution of the sample is irreversible above $873 \mathrm{~K}$, which indicates that the decrease in magnetization cannot be due to a ferro-paramagnetic transition but due to a new crystallization process. Similar observation was also made by Blazquez et al. ${ }^{17,40}$ This irreversible decrease in $\mathrm{M}$ advances in each repeated heating-cooling runs, as the crystalline fraction of the new phase increases. This is in agreement with DSC: although DSC peak was not seen because of the limited temperature range in the present study, it is clear that the curve is not returning to the baseline in the high temperature region, which might indicate that another peak is beginning close by.

Earlier studies on $\mathrm{FeCoNbBCu}$ alloy suggest that the recrystallisation process with a lowering of the volume fraction of the magnetic phase to form some non-magnetic phase is responsible for the decrease in $\mathrm{M}^{40}$ Our Mössbauer study also supports this finding by the evidence of Nb-rich nonmagneitc phase in case of nanocrystalline specimens. Therefore, the volume fraction of ferromagnetic phase decreases to form the non-magnetic niobate phase. At higher temperature, the increase in $\mathrm{M}$ suggests another crystallization process, with the formation of boride and niobate phases. ${ }^{42}$

\section{CONCLUSION}

The effect of isochronal annealing on the microstructure and magnetic properties of the $\mathrm{Fe}_{40.5} \mathrm{Co}_{40.5} \mathrm{Nb}_{7} \mathrm{~B}_{12}$ was investigated. The anomalous XRD and Mössbauer measurements jointly provide evidence for atomically ordered $\alpha^{\prime}$-FeCo phase as the nanocrystalline ferromagnetic phase. The isochronal annealing treatment results in randomly oriented nanocrystallites with refined nanocrystalline grains of size $\sim 8-13 \mathrm{~nm}$; this suggests that alloy should posses improved soft magnetic properties such as low coercivity. Simultaneous presence of non-magnetic $\mathrm{Nb}$ rich phase with fraction of $\mathrm{Fe}$ atoms as high as $19 \%$ along with FeCo nanocrystalline phase was also confirmed from Mössbauer spectroscopy in the alloy annealed above $723 \mathrm{~K}$. However, the same was not detected from SR-XRD and TEM measurements, which may be due to smaller crystallite size and/or high degree of disorder. Electron microscopy measurements reveal that the grains of fcc- $(\mathrm{FeCo})_{23} \mathrm{~B}_{6}$ phase together with bcc-Fe(Co) started developing after annealing at $948 \mathrm{~K}$ and were fully developed upon annealing at $973 \mathrm{~K}$. The thermal evolution of the alloy is irreversible, which is evidenced by re-crystallization process involving the FeCo-nanocrystalline phase. This recrystallization process with a lowering of the volume fraction of the magnetic FeCo phase to form some non-magnetic $\mathrm{Nb}$ rich phase is responsible for the decrease in magnetization above $873 \mathrm{~K}$.

\section{ACKNOWLEDGMENTS}

The authors are thankful to Dr. P. D. Gupta for his encouragement and support. Thanks are due to Mr. Manvendra Singh and Mr. Anuj Upadhyay for their help and support during the beam time at ADXRD beamline, Indus-2, India. Mr. Anil is acknowledged for providing support during Mössbauer measurements. Thanks are also to Dr. A. M. Awasthi and Mr. Suresh Bharadwaj for providing DSC facility. One of the authors PSJ acknowledges project VEGA 2/0111/11 for the support. V.F. acknowledges the support from the Spanish Ministry of Science and Innovation and EU FEDER (Project MAT 2010-20537) and the PAI of the Regional Government of Andalucía (Project P10-FQM-6462).

${ }^{1}$ Y. Yoshizawa, S. Oguma, and K. Yamauchi, J. Appl. Phys. 64, 6044 (1988).

${ }^{2}$ K. Suzuki, A. Makino, N. Kataoka, A. Inoue, and T. Masumoto, Mater. Trans., JIM 32, 93 (1991).

${ }^{3}$ M. E. McHenry, M. A. Willard, and D. E. Laughlin, Prog. Mat. Sci. 44, 291 (1999).

${ }^{4}$ G. Herzer, J. Mag. Mag. Mater. 294, 99 (2005).

${ }^{5}$ K. E. Knipling, M. Danil, and M. A. Willard, Appl. Phys. Lett. 95, 222516 (2009).

${ }^{6}$ K. Pekala, J. Non-Cryst.Solids 354, 5304 (2008) and references therein.

${ }^{7}$ I. Škorvánek, P. Švec, J. Marcin, J. Kováč, T. Krenický, and M. Deanko, Phys. Status Solidi A 196, 217 (2003) and references therein.

${ }^{8}$ D. H. Ping, Y. Q. Wu, K. Hono, M. A. Willard, M. E. McHenry, and D. E. Laughlin, Scr. Mater. 45, 781 (2001).

${ }^{9}$ J. S. Blazquez, V. Franco, A. Conde, and L. F. Kiss, J. Mag. Mag. Mater. 262, 170 (2003).

${ }^{10}$ J. S. Blazquez, V. Franco, and A. Conde, J. Phys.: Condens. Matter. 14, 11717 (2002).

${ }^{11}$ Properties and Applications of Nanocrystalline Alloys from Amorphous Precursors, edited by C. F. Conde, J. S. Blazquez, and A. Conde (Kluwer, Dordrecht, 2005).

${ }^{12}$ M. A. Willard, D. E. Laughlin, and M. E. McHenry, J. Appl. Phys. 84, 6773 (1998).

${ }^{13}$ B. D. Cullity, Elements of X-ray Diffraction (Addison-Wesley, 1956).

${ }^{14}$ A. K. Sinha, A. Sagdeo, P. Gupta, A. Kumar, M. N. Singh, R. K. Gupta, S. R. Kane, and S. K. Deb, AIP Conf. Proc. 1349, 503 (2011).

${ }^{15}$ J. S. Blazquez, C. F. Conde, A. Conde, J. M. Greneche, J. Alloys Compd. 370, 36 (2004).

${ }^{16}$ L. Kraus, V. Hašlar, P. Duhaj, P. Švec, V. Studnička, Mater. Sci. Eng. A 226-228, 626 (1997).

${ }^{17}$ J. S. Blazquez, C. F. Conde, and A. Conde, J. Non-Cryst. Solids 287, 187 (2001). 
${ }^{18}$ A. P. Hammersley, ESRF Internal Report ESRF98HA01T, FIT2D V9.129 Reference Manual V3.1 (1998).

${ }^{19}$ International Centre of Diffraction Data PDF-2 Database, 2002.

${ }^{20} \mathrm{C}$. Hammond, The Basics of Crystallography and Diffraction (Oxford University Press, 2009).

${ }^{21}$ P. Scherrer, Gott. Nachr. 2, 98 (1918).

${ }^{22}$ P. Gupta, A. Gupta, V. Franco, and A. Conde, J. Appl. Phys. 101, 033909 (2007).

${ }^{23}$ G. K. Williamson and W. H. Hall, Acta Metall. 1, 22 (1953).

${ }^{24}$ P. Kameli, H. Salamati, and A. Aezami, J. Appl. Phys. 100, 053914 (2006).

${ }^{25}$ G. Herzer, IEEE Trans. Magn. 26, 1397 (1990).

${ }^{26}$ A. Gupta, N. Bhagat, G. Principi, and A. Hernando, J. Magn. Magn. Mater. 133, 291 (1994).

${ }^{27}$ P. Gupta, A. Gupta, G. Principi, A. Maddalena, S. Bernstorff, and H. Amenitsch, J. Appl. Phys. 101, 053907 (2007).

${ }^{28}$ J. S. Bl'azquez, A. Conde, and J. M. Grenèche, J. Phys.: Condens. Matter 15, 7843 (2003).

${ }^{29}$ B. Demayo, D. W. Forester, and S. Spooner, J. Appl. Phys. 41, 1319 (1970).

${ }^{30}$ J. Zbroszczyk, Nukleonika 52, S29 (2007).

${ }^{31}$ B. E. Warren, X-Ray Diffraction (Addison Wesley, 1969).
${ }^{32}$ A. Gunier, X-Ray Diffraction in Crystals, Imperfect Crystals and Amorphous Bodies (Freeman, San Francisco, 1963).

${ }^{33}$ G. Principia, A. Maddalena, M. Meyer, S. Dal Toe, A. Gupta, P. Sharma, B. A. Dasannacharya, N. Paul, S. Bernstorff, and H. Amenitsch, J. Magn. Magn. Mater. 272-276, 1441 (2004).

${ }^{34}$ R. A. Brand, J. Lauer, and D. M. Herlach, J. Phys. F: Met. Phys. 14, 555 (1984).

${ }^{35}$ P. Panissod, J. Durand, and J. I. Budnick, Nucl. Instrum. Methods Phys. Res. 199, 99 (1982)

${ }^{36}$ S. N. Kane, A. Gupta, S. D. Sarabhai, and L. Kraus, J. Magn. Magn. Mater. 254, 495 (2003).

${ }^{37}$ F. H. Sanchez, J. I. Budnick, Y. D. Zhang, W. A. Hines, and M. Choi, Phys. Rev. B 34, 4738 (1986).

${ }^{38}$ T. Shinjo and W. Keune, J. Magn. Magn. Mater. 200, 598 (1999).

${ }^{39}$ J. S. Blazquz, S. Lozano-Perez, and A. Conde, Philos. Mag. Lett. 82, 409 (2002).

${ }^{40}$ J. S. Blázquez, C. F. Conde, and A. Conde, Appl. Phys. Lett. 79, 2898 (2001).

${ }^{41}$ P. Gupta, T. Ganguli, A. Gupta, A. K. Sinha, S. K. Deb, and P. Svec Jr., in Proceedings of the 56th DAE Solid State Physics Symposium 2011.

${ }^{42}$ T. Krenický, J. Marcin, I. Škorvánek, and P. Švec, Czech. J. Phys. 54, 185 (2004). 